\title{
Spatio-Temporal Distribution and Characterization of Microplastic Pollution in The Three Main Freshwater Systems (Aksu and Köprü Streams, Manavgat River) And Fishing Grounds Located in Their Vicinities in The Antalya Bay
}

\author{
Olgaç Guven $^{1, *}$ (1) \\ ${ }^{1}$ Akdeniz University, Faculty of Fisheries, 07058, Antalya, Türkiye
}

\section{How to cite}

Guven, O. (2022). Spatio-Temporal Distribution and Characterization of Microplastic Pollution in The Three Main Freshwater Systems (Aksu and Köprü Streams, Manavgat River) And Fishing Grounds Located in Their Vicinities in The Antalya Bay. Turkish Journal of Fisheries and Aquatic Sciences, 22(SI), TRJFAS20507. http://doi.org/10.4194/TRJFAS20507

\section{Article History}

Received 24 August 2021

Accepted 15 November 2021

First Online 17 November 2021

\section{Corresponding Author}

Tel.: +905327895963

E-mail: olgac@akdeniz.edu.tr

\section{Keywords}

Microplastic pollution

Freshwater systems

Characterization

Abundance

\begin{abstract}
Microplastic pollution is one of the pressing environmental issues over the world that pose risks to aquatic ecosystems and humans. Significant amount of anthropogenic plastic litter known to be transported with freshwater systems to marine environment. The aim of the present study is to reveal the abundance and spatio-temporal distribution of MPs pollution in the three main freshwater systems (Aksu and Köprü Streams, Manavgat River), located through the costal line of the Antalya Bay. 106 water samples obtained from these three freshwater systems and fishing grounds located in the vicinities of these systems were evaluated. A total of 2444 MPs with a mean size of $1777.16 \pm 1168.81 \mu \mathrm{m}$ detected within these samples. A homogeneous MPs pollution was observed in the area. Four colours (Black-27.3\%, White-19.4\%, Red$18.7 \%$ and Blue-16.2\%) found to composed more than $80 \%$ of the detected MPs. Majority of MPs detected within the framework of the study were fiber $(57.1 \%)$ and fragment (32.6\%). Most common polymer type was Polyproplene-(PP) with $50 \%$. Results obtained from this study have the potential to form the basis for future studies that take into account the terrestrial use and the prevailing physical factors in the region in the study area.
\end{abstract}

\section{Introduction}

Today plastic pollution is one of the pressing environmental issues over the world and its impact on environment is a global concern. In addition to waste plastic litter already available in the environment, the increasing production of disposable plastic products constitutes a major obstacle to coping with the plastic pollution crisis. The efforts made on the subject show that half of the total plastic manufacturing have been done in the last 15-year period (Parker, 2019). Considering the increase in the world population since 1950 and the increase in plastic production observed in parallel, it is predicted that in 2050 an additional 33 billion tons of plastic waste will be advance to the current plastic pollution and accumulate around our planet (UNEP, 2016). Although it is known that a significant amount of plastic litter ends up terrestrial environment due to the mismanaged wastes, oceans are the final accumulation area for these wastes. Rivers and other watercourses are the main transport routes of the plastic debris released by anthropogenic activity on land (UNEP, 2016). By several researchers it is stated that the interpretation of the temporal trends of plastic waste reaching the marine environment via rivers requires a complex evaluation due to seasonal changes. Moreover, 
seasonal variations, due to differences in sampling seasons, environmental conditions, and sampling approaches, of the MPs pollution under the influence of physical and chemical characteristics of the aquatic environment is a known fact (Wang et al., 2021; Xia et al., 2021). Though time-dependent variation has been addressed in a limited number of studies.

Mediterranean Sea is a semi-closed system which is under intense coastal population pressure. Moreover, with the contribution of many sectoral activities, such as tourism, industrial, shipping and fishing, operating in the region, the Mediterranean is a hot spot for plastic pollution. As an consequence of populated areas around river basins, rivers were accepted to play an important role in the transport of plastic wastes to the marine environment (Cózar et al., 2015). Within the assessment report of the United Nations Environment Programme, Mediterranean Action Plan (UNEP-MAP) Turkey was stated to be the one of the leading counties which contributes largely to pollution (144 tons.day ${ }^{-1}$ ) in the region (UNEP MAP, 2015). Additionally, a model study covering all Mediterranean Region reports highest percentage of plastic litter generation from Turkish terrestrial region that contributes to floating debris

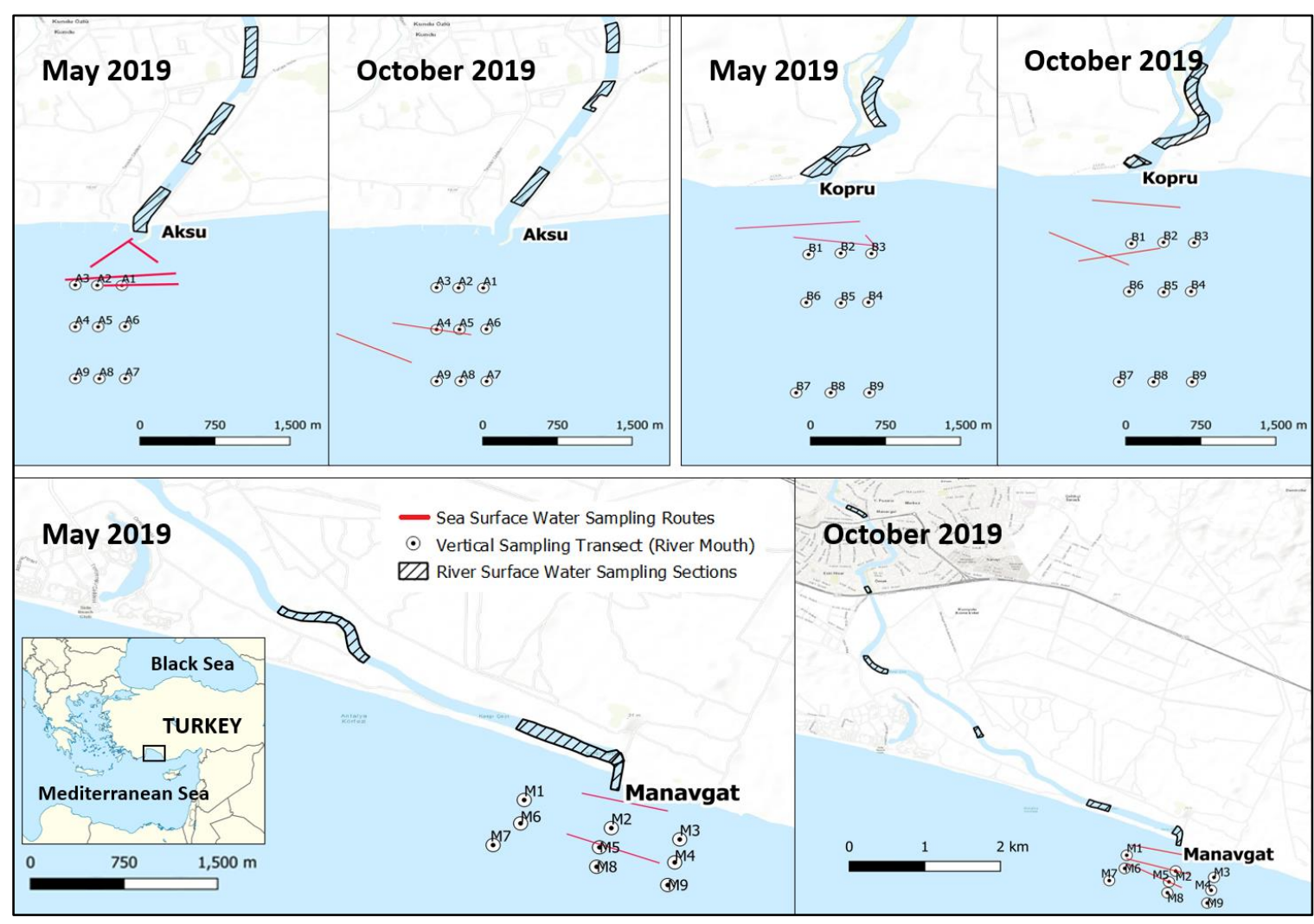

Figure 1. Geographical position of evaluated freshwater systems and sampling zones.

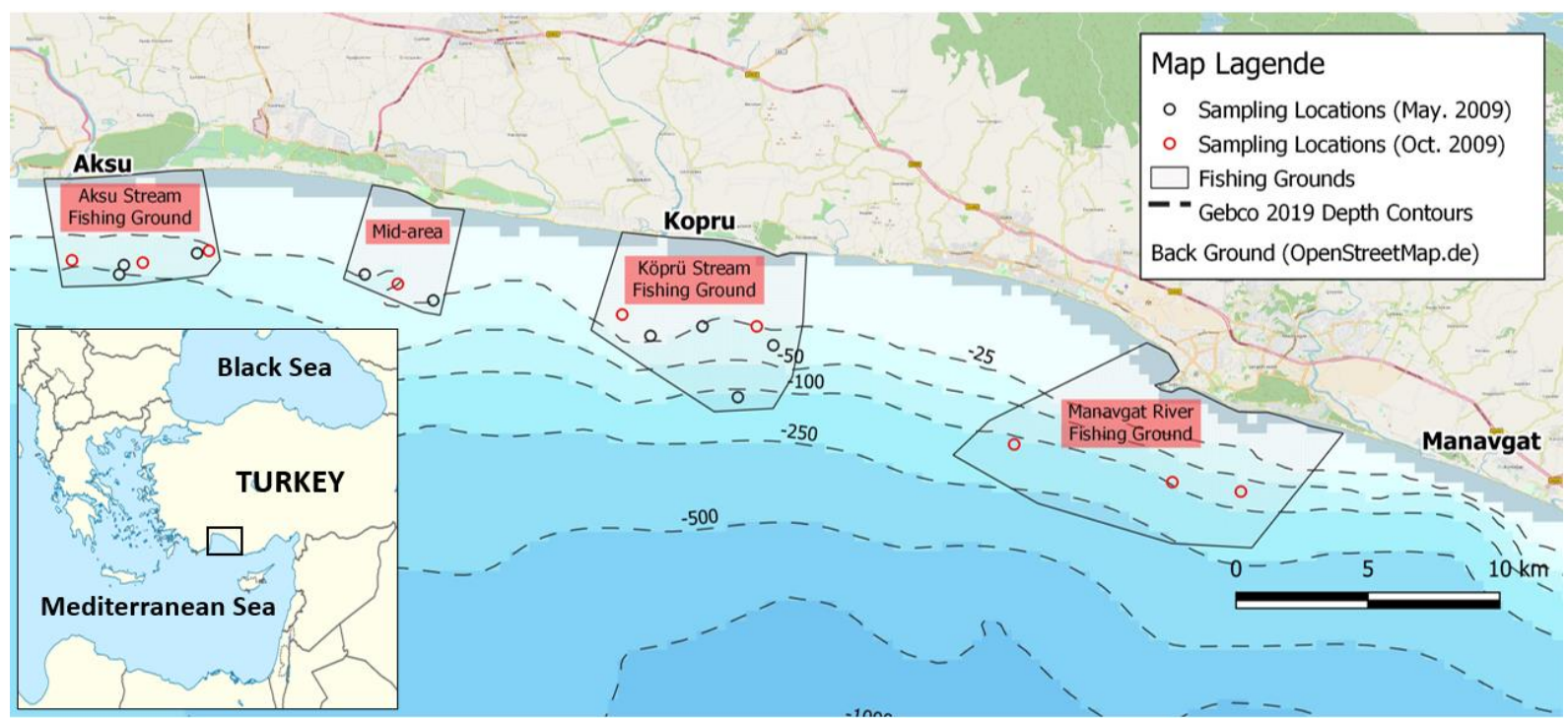

Figure 2. Geographical position of evaluated fishing grounds and location of the sampling points. 
compare to other countries in the region (Liubartseva et al., 2018). Present study was designed to reveal the abundance and spatio-temporal distribution of MPs pollution in the three main freshwater systems (Aksu and Köprü Streams, Manavgat River), located through the costal line of the Antalya Bay. In addition to the freshwater systems, four open water fishing grounds located in the vicinities of these systems also evaluated.

\section{Materials and Methods}

\section{Study Area and Sampling Design}

Present study was carried out in Antalya Bay in two different time frames determined considering the rain season (May 2019 and October 2019). Antalya Basin, which completely covers the terrestrial side of the Antalya Bay, has a population of over two million. Tourism activities continue throughout all four seasons, indoor and outdoor agricultural activities are also carried out intensively due to its climatic characteristics. Three freshwater systems subject to our study were the sub basins of the Antalya Basin. 25.6\% the drainage area of the Antalya Basin is agricultural land while rate of the forest, semi-natural land and urban areas were $69.9 \%$ and $1.6 \%$ respectively (TÜBITAK MAM ÇTÜE, 2013). Three main freshwater systems (Aksu and Köprü Streams, Manavgat River), located through the coastal line of the bay, with high freshwater flow rates were evaluated in order to understand the impact of rain season on the status of microplastic pollution. Both river surface and river mouths were included in the scope of

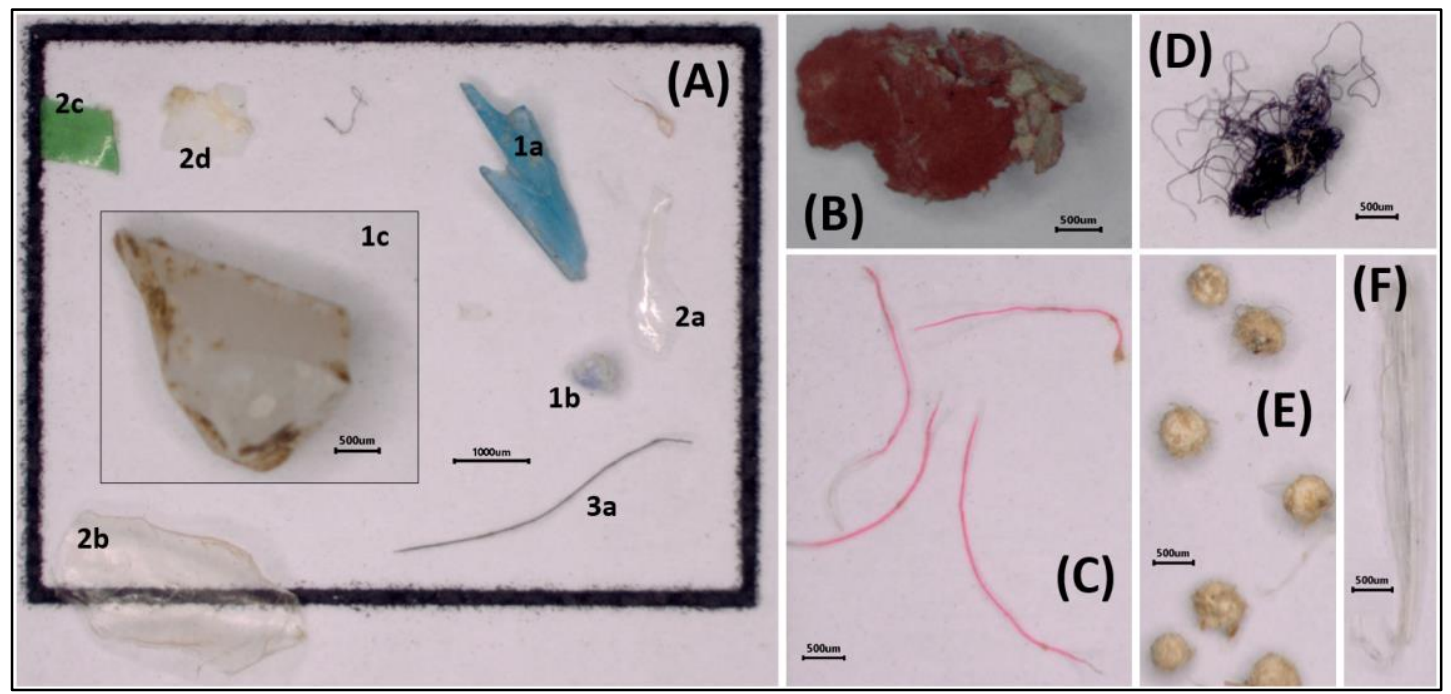

Figure 3. Images of MPs particles detected within the framework of the study (Fragment: A1a-c, F; Film: A2a-d; Fiber: A3a, C and D; Paint particle: B; Foams: E)

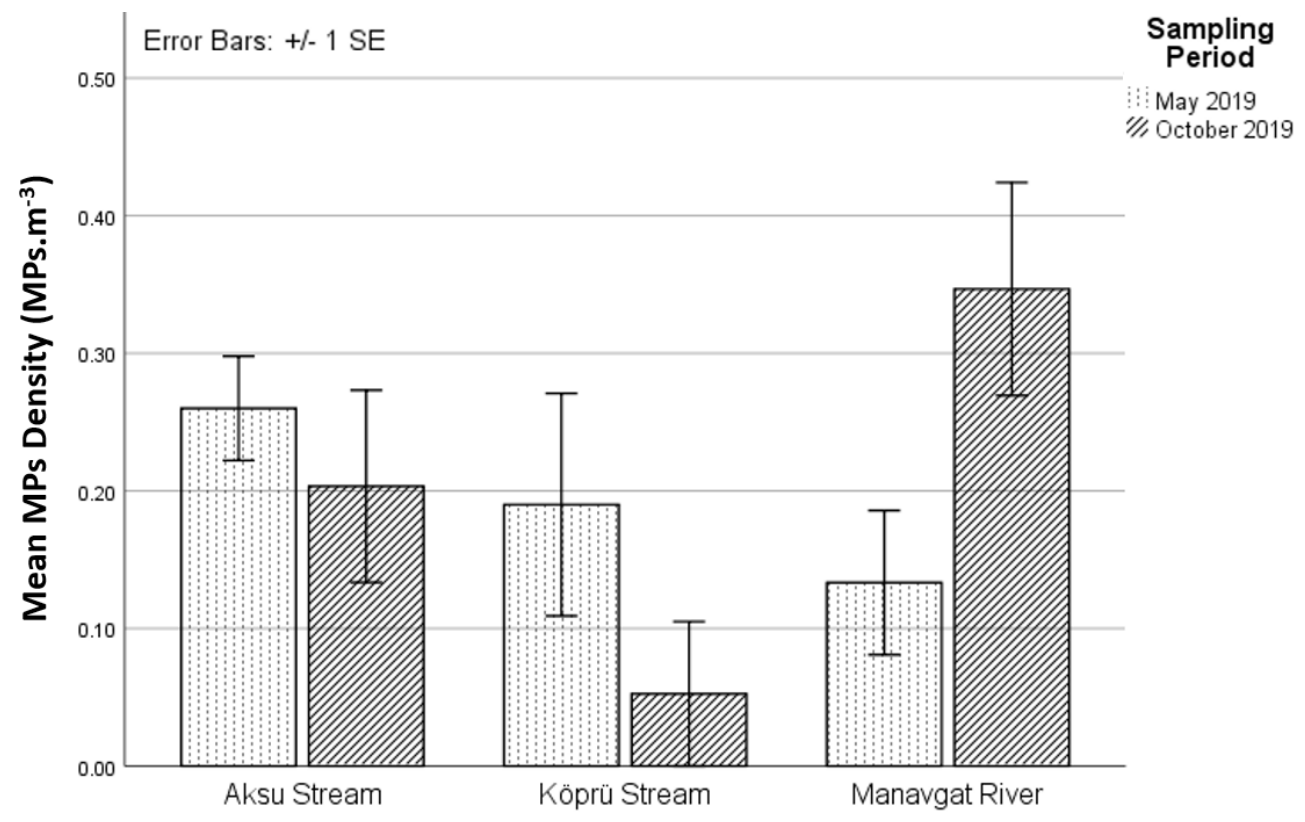

Freshwater Systems

Figure 4. MP abundance in the freshwater systems for two different sampling periods. 
assessment (Figure 1). Moreover, four different fishing grounds, located in the vicinities of these freshwater systems and one mid-zone located between Aksu and Köprü Streams were also evaluated (Figure 2). A total of 108 water samples were evaluated within the framework of the current study. Detailed table of sampling location coordinates were given in SM1.

Freshwater and sea surface waters located in the mouth region of the evaluated freshwater systems were sampled using a manta net sampling system $(333 \mu \mathrm{m}$ mesh size). Withal water column of the river mouth sites and commercial trawling grounds were sampled using a
WP2 plankton sampler (200 $\mu \mathrm{m}$ mesh size). For the river mouth sites, vertical sampling was carried out as a $3 \times 3$ transect ( $250 \mathrm{~m}$ distance between sampling points) covering right, across and left side of the river mouths and 5, 10 and $15 \mathrm{~m}$ depths. All water column sampling was carried out onboard the R/V "Akdeniz Su" while water surface sampling was done using a zodiac boat. During surface sampling, in order to prevent turbulent flow of the propeller towing point of the manta net system situated $5 \mathrm{~m}$ away from the boat. Prior to laboratory analysis water samples were stored in glass jars and at a low temperature $\left(4^{\circ} \mathrm{C}\right)$ in the dark.

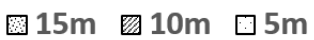

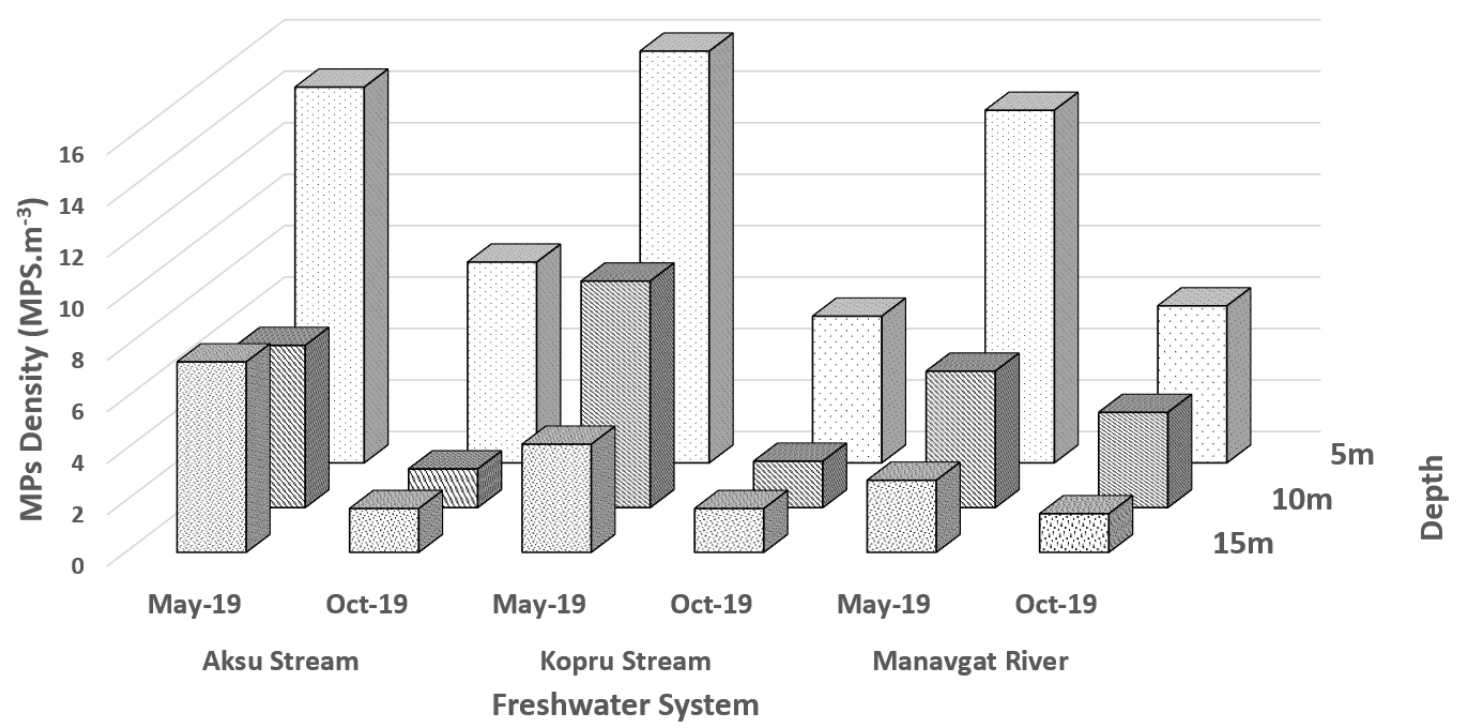

Figure 5. Water column MP abundance in the river mouth areas for two different sampling periods.

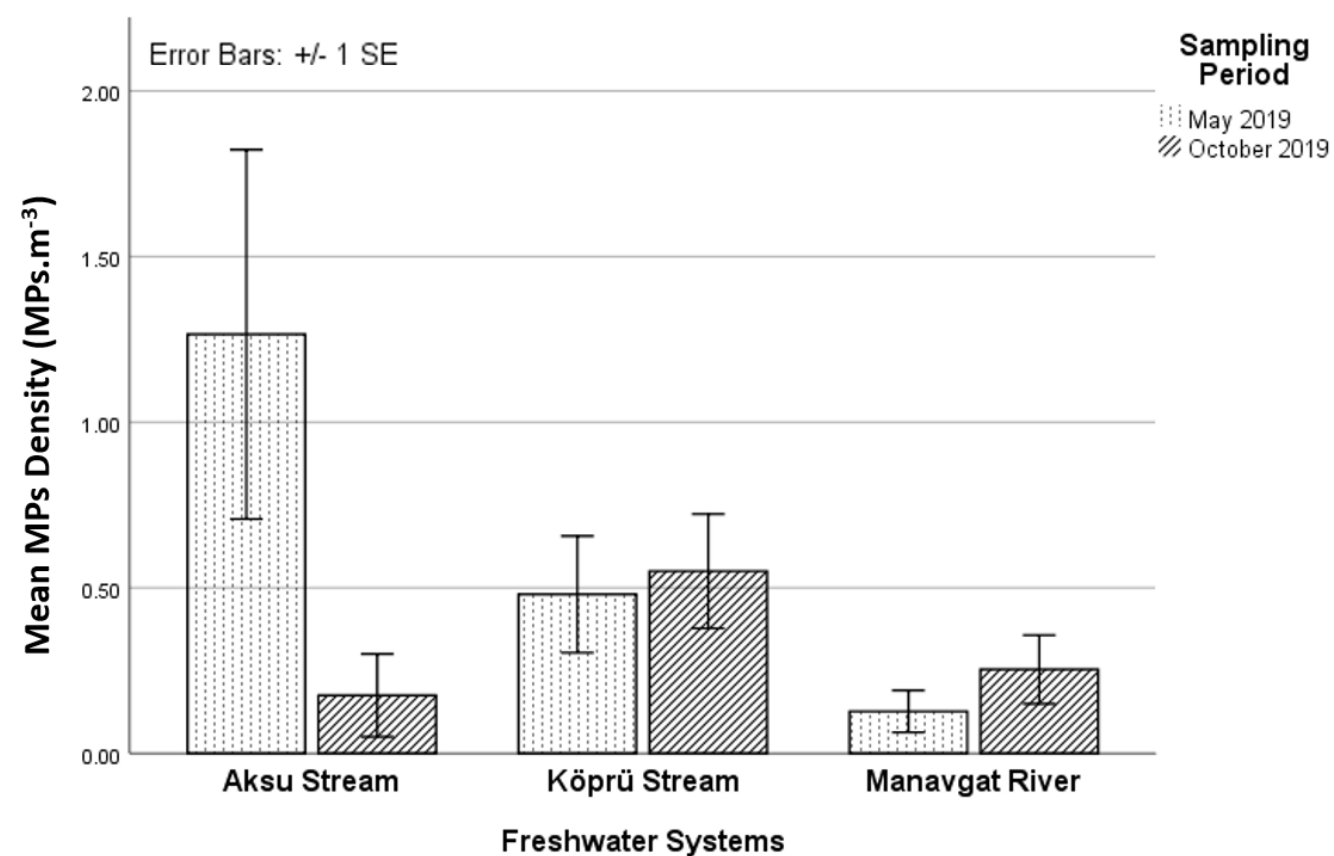

Figure 6. Surface water MP abundance in the river mouth areas for two different sampling periods. 


\section{Laboratory Analysis}

To remove the particles larger than $5 \mathrm{~mm}$, water samples were visually inspected and sieved through coarse mesh. In order to remove the available organic matter in the water samples, a digestion step with $1 \mathrm{M}$ $\mathrm{KOH}$ solution was carried out for 7 days at $60^{\circ} \mathrm{C}$ (Nie et al., 2019). Following the digestion step, solutions were filtered through a $26 \mu \mathrm{m}$ mesh sized filters using a vacuum filtration unit. Visual detection of the MPs was carried out with an Olympus SZX16 Stereo microscope (max. 11,5X) equipped with DP25 - Olympus5.0 MP High Colour Fidelity Microscope Digital Camera. Detected particles were classified by colour and physical characteristics in accordance to the morphological characterization recommendation by GESAMP (2019) and visual records were taken. Using these records longest side length of each particle measured with Oympus DP2-BSW software running parallel to the microscope system.

\section{Contamination Control}

In order to minimize the inevitable airborne in-lab fiber contamination great care was paid. Prior to use all glassware and dissection tools were rinsed with distilled water. For filtration and microscope examination steps, 'procedure controls' (150 $\mathrm{mm} \varnothing$ glass beakers filled with distilled water) were present in the working area. Plastic fiber particles detected in these procedure controls were also classified in accordance with their colour and measured (length and diameter). Following a cross check, detected similar MPs (same colour, same size and same diameter), within the environment samples data set were removed to prevent the over estimation.

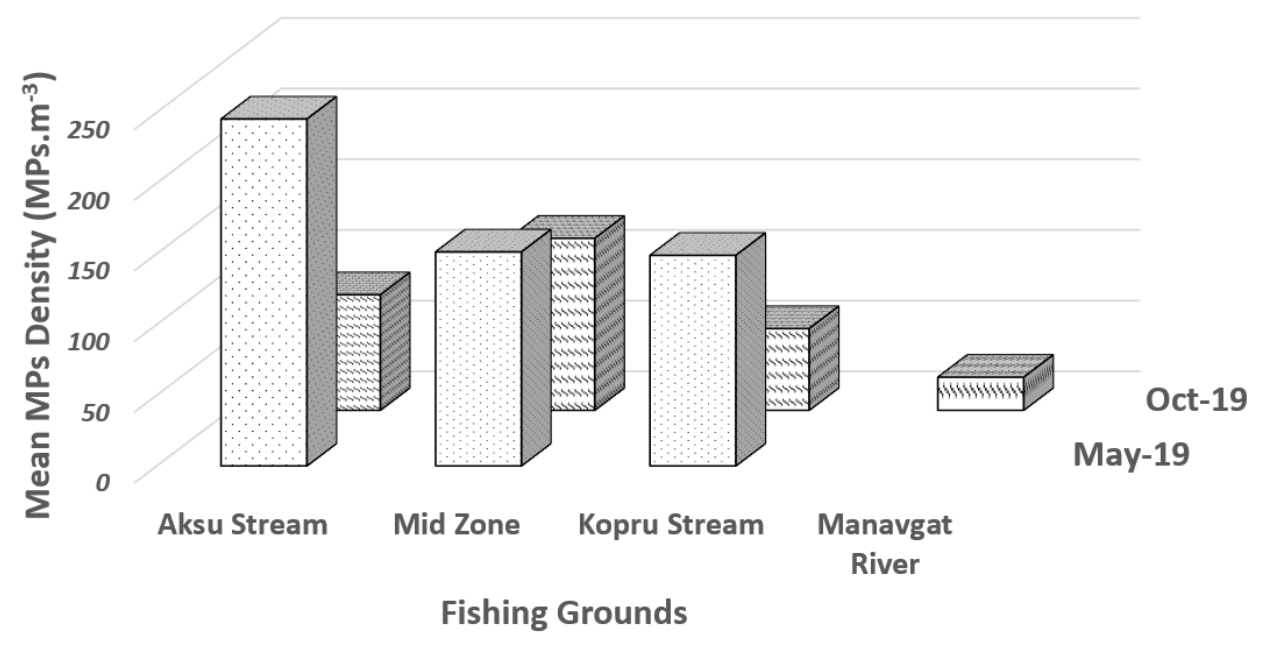

Figure 7. Water column MP abundance in the fishing grounds for two different sampling periods.

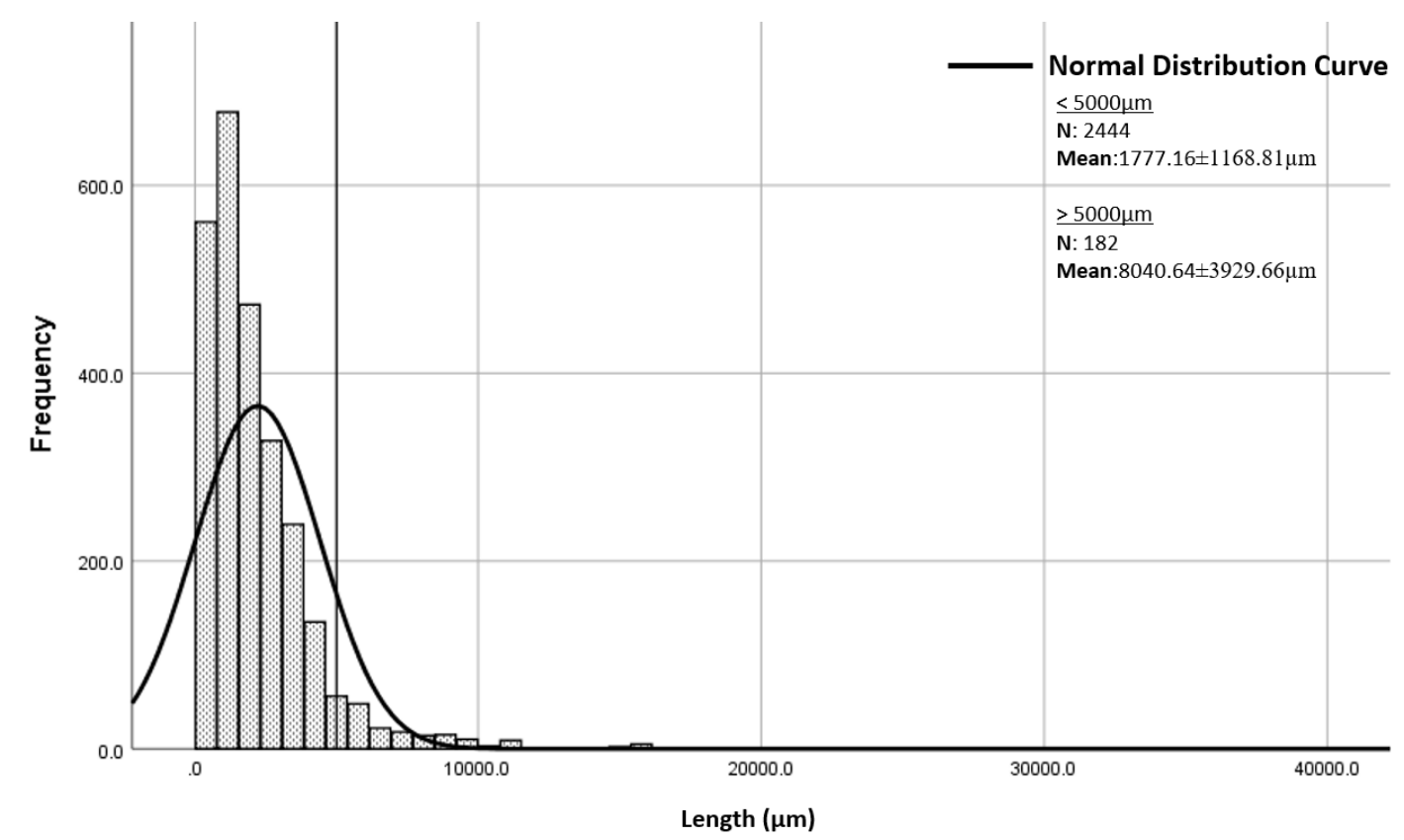

Figure 8. Size frequency distribution of detected plastic particles. 


\section{Polymer Analysis}

In accordance with the classification made considering the physical properties of the detected microscopic particles under the light microscope, a subsample of MPs (a total of 32 particles) was created that represent the entire sample. ATR- $\mu \mathrm{FT}-\mathrm{IR}$ analysis of the sub-sample was carried out with micro-FTIR (Nicolet ${ }^{\mathrm{TM}}$ iN10 FTIR, USA) that equipped with a germanium ATR attachment. By matching the spectrums in several reference libraries polymer types of the samples were identified in KnowltAll software (Jonn Wiley \& Sons Inc.). The spectrums were compared with relevant KnowltAll IR Spectral Libraries with Search $T^{T M}$ toolbox with the extraction of spectral ranges corresponds to carbon dioxide $\left(2250-2500 \mathrm{~cm}^{-1}\right)$ and water vapour ranges $\left(3250-3900 \mathrm{~cm}^{-1}\right.$ and $\left.1350-2000 \mathrm{~cm}^{-1}\right)$. Nevertheless, peaks present in the excluded sections were visually inspected and evaluated with Minelt ${ }^{\mathrm{TM}}$ toolbox prior the final polymer type decision.

\section{Statistical Analysis}

Rank-based nonparametric Kruskal-Wallis $\mathrm{H}$ test was conducted to determine the possible spatial and temporal differences in detected MPs densities from river systems, river mouth areas and fishing grounds. Results, unless differently indicated, were expressed as the arithmetic mean \pm standard deviation (SD). To determine whether colour-type of MPs and subdomains evaluated within the study area are statistically independent Chi-square test for association was conducted. Statistical analysis was per-formed using SPSS 26 software (IBM SPSS, 2021)

\section{Results}

Prior to sharing the results of the study, it is necessary to express a case encountered during the study in order to prevent an overestimation of MPs pollution state in the study area. One dominant particle type, the claret paint particles (a total number of 659) (Figure B) with a mean length of $1.7 \pm 1.2 \mathrm{~mm}$, detected in the water column samples collected from both the fishing ground and river mouth stations. Due to the fact that such an un expected intense pollution caused by only one type of MPs encountered, a detailed examination of sampling equipment and research vessel was made. It was detected that these particles were originated from the protection coating applied to

Table 1. MPs abundances (MPs. $\mathrm{m}^{-3}$ ) detected in the study area for the two sampling periods. (FW: Surface waters of the river systems, RM: Surface waters of the river mouth areas, RMT: Water column of the river mouth areas).

\begin{tabular}{|c|c|c|c|c|c|c|}
\hline & \multicolumn{2}{|c|}{ Aksu Stream } & \multicolumn{2}{|c|}{ Köprü Stream } & \multicolumn{2}{|c|}{ Manavgat River } \\
\hline & May-19 & Oct-19 & May-19 & Oct-19 & May-19 & Oct-19 \\
\hline FW & $0.3 \pm 0.1$ & $0.2 \pm 0.1$ & $0.2 \pm 0.2$ & 0.2 & $0.2 \pm 0.1$ & $0.4 \pm 0.2$ \\
\hline RM & $1.4 \pm 1.2$ & $0.1 \pm 0.2$ & $0.5 \pm 0.3$ & $0.6 \pm 0.3$ & $0.2 \pm 0.0$ & $0.3 \pm 0.2$ \\
\hline \multicolumn{7}{|l|}{ RMT } \\
\hline \multicolumn{7}{|c|}{ Depth contour } \\
\hline $5 m$ & $14.6 \pm 14.9$ & $7.8 \pm 6.5$ & $16.0 \pm 7.6$ & $5.7 \pm 1.4$ & $13.7 \pm 2.5$ & $6.1 \pm 2.3$ \\
\hline $10 \mathrm{~m}$ & $6.3 \pm 0.5$ & $1.5 \pm 1.7$ & $8.8 \pm 1.5$ & $1.8 \pm 1.1$ & $5.3 \pm 3.1$ & $3.7 \pm 0.5$ \\
\hline $15 \mathrm{~m}$ & $7.4 \pm 4.2$ & $1.7 \pm 0.9$ & $4.2 \pm 4.1$ & $1.7 \pm 0.5$ & $2.8 \pm 1.1$ & $1.5 \pm 0.4$ \\
\hline
\end{tabular}

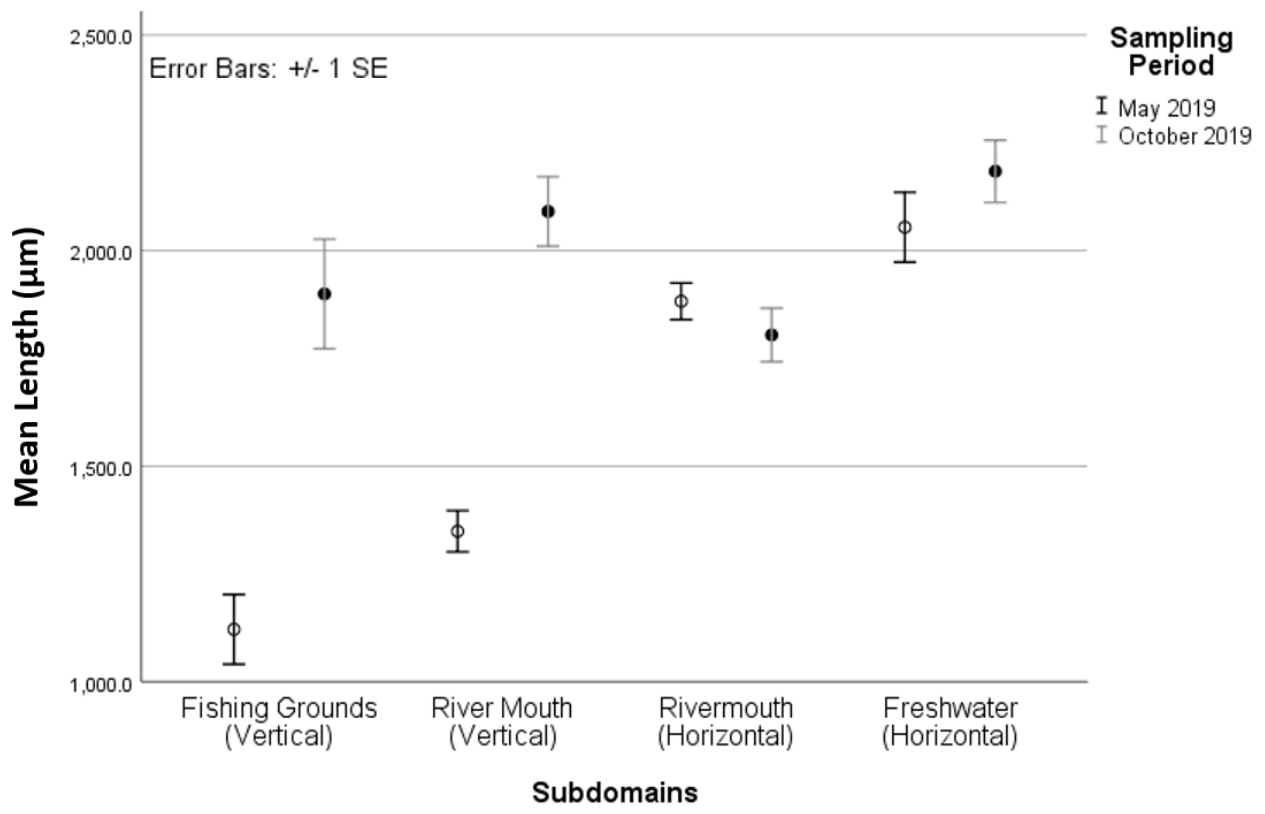

Figure 9. Mean length of MPs from subdomains of the study by sampling period. 
prevent the accumulation of microorganisms to the research vessel. Although these particles were collected from sampling area and was a part of existing MPs pollution, data related with these particles have been removed from the data set to properly examine the pollution status of the fishing grounds, excluding the sampling effect.

\section{Abundance of MPs}

A total of 2444 MPs were detected in 106 water samples collected from 3 different rives systems and their vicinities. A biannual assessment of MPs abundance was carried out in the three subdomains of the study area. The abundance of MPs in was expressed as number of MPs per cubic meter (MPs. $\mathrm{m}^{-3}$ ). Detected total - mean number of MPs and mean densities in the study area (freshwater systems) were given in Table 1.

\section{River Waters}

A total of 517 MPs were detected from the surface waters of the three freshwater systems evaluated. To determine if the rain season has an impact on the MPs loads of the freshwater systems, a K-W H test was run. Results indicated no statistically significant difference between sampling seasons $\left(\chi^{2}(2)=.941, p=.332\right)$. Although for May 2019 period Aksu Stream and for October 2019 period Manavgat River detected to be most polluted systems in terms of MPs abundance, $0.3 \pm 0.1 \mathrm{MPs} . \mathrm{m}^{-3}$ and $0.3 \pm 0.2 \mathrm{MPs}^{-3} \mathrm{~m}^{-3}$ respectively, $\mathrm{K}-\mathrm{W}$ $\mathrm{H}$ test indicated no statistically significant difference between the freshwater systems $\left(\chi^{2}(2)=4.388, p=.111\right)$ (Figure ). It was detected that neither the sampling season nor the MPs pollutant potential of the freshwater system were not effective on state of MPs pollution in the study area in terms of MPs abundance.

\section{River Mouth}

With a total of 1709 MPs detected (surface water: $961 \mathrm{MPs}$ and water column $748 \mathrm{MPs}$ ), river mouth regions were the most polluted areas in the entire study area. Both water surface and water column of the river mouth regions were evaluated in order to reveal the MPs pollution status and its seasonal variation. $\mathrm{K}-\mathrm{W} \mathrm{H}$ test was run to determine if there were differences in state of MPs pollution between water column samples collected from three river mouths (Figure ). In contrast to the situation in freshwater systems a statistically significant MPs abundance difference was detected between sampling periods in the water column samples of the river mouths, $\chi^{2}(1)=14.990, p=.000$. May 2019 $\left(9.5 \pm 6.8 \mathrm{MPs}^{-3}\right)$ found to be almost three times polluted then October $2019\left(3.5 \pm 3.1 \mathrm{MPs}^{-3}\right.$ ) (Figure 5). In addition, $\mathrm{K}-\mathrm{W} \mathrm{H}$ test have indicated no significant MPs abundance difference between the water column samples of the river mouth regions of the studied freshwater systems in both sampling periods (May-09: $\chi^{2}(2)=1.087, p=.581$ and October-09: $\chi^{2}(2)=1.564, p=$ .457). In terms of depth ranges, although the mean MPs densities of the water column samples were detected to be higher in $5 \mathrm{~m}$ depth contour in general, the only statistically significant difference was detected for the samples (between $5 \mathrm{~m}$ and $15 \mathrm{~m}$ ) collected from Manavgat River $\left(\chi^{2}(2)=2.470, p=.041\right)$. A homogeneous MPs pollution, which tends to change over sampling periods, was observed in the water column of evaluated freshwater systems.

Like the seasonal MPs pollution state of the freshwater systems, no seasonal difference was detected for either of the river mouth surface waters $\left(\chi^{2}(1)=0.387, p=.534\right)$. Moreover, no statistically significant difference between the river mouth surface waters of the different river systems detected $\left(\chi^{2}(2)\right.$ =4.789, $p=.091$ ). Although the mean MPs abundance detected from Aksu Stream samples in May 2019 sampling period $\left(1.26 \pm 1.12 \mathrm{MPs}^{-3} \mathrm{~m}^{-3}\right)$ was much higher than other detected pollution densities, due to the high standard variation value no statistical difference was observed in the comparisons (Figure ).

\section{Fishing Grounds}

Nine stations, representing 4 different fishing grounds, were included in the assessment of MPs pollution state in the sampling area for both sampling periods (May 2019 and October 2019) (Figure ). A total
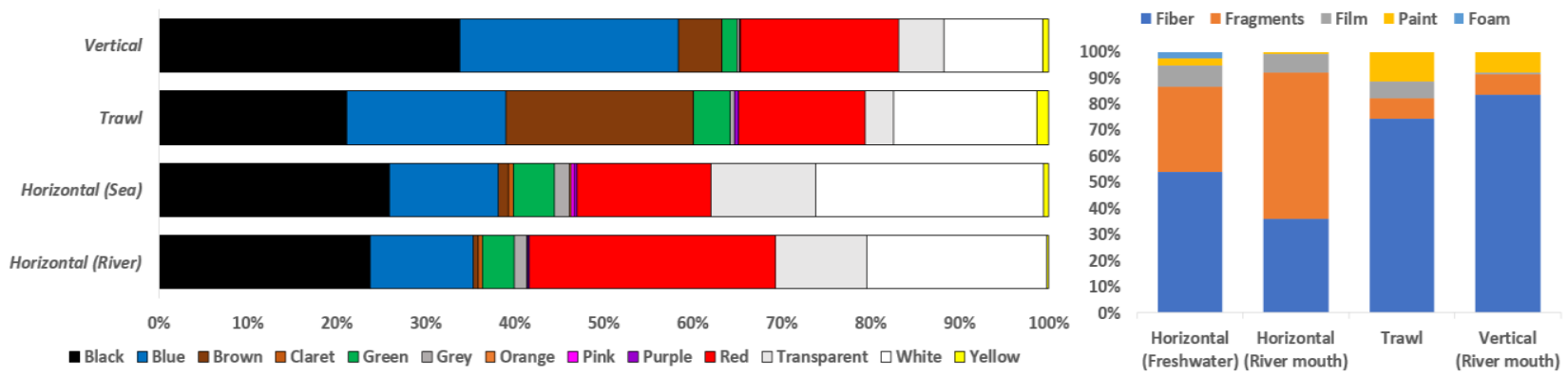

Figure 10. Colour and type distribution of MPs in the sub-domains of the study area (Trawl: Water column samples from Fishing grounds) based on colour and physical characteristics. 
of 218 MPs were detected within the water column samples collected from both sampling seasons. Except for mid zone (fishing ground located between Aksu and Köprü Stream vicinities), which was the most polluted fishing ground, an increasing pollution state was observed as the evaluated grounds get closer to Antalya city centre. Like the MPs pollution pattern, MPs densities were also detected to be same for both sampling periods $\left(\chi^{2}(1)=2.676, p=.102\right)$. Although highest MPs pollution was detected in May 2019 (483.6 MPs. $\mathrm{m}^{-3}$ ) with more than 4 folds of the average MPs abundance detected for the entire study area, due to the wide MPs abundance variation between the Aksu Stream vicinity fishing ground samples, no significant statistical difference between evaluated fishing grounds was detected $\left(\chi^{2}(3)=6.557, p=.087\right)$.

\section{Morphological Characteristics of MPs}

The mean MPs size detected in the study area was $1.8 \pm 1.2 \mathrm{~mm}$ (range: $0.35-4.96 \mathrm{~mm}$ ). There appears to be a difference between the sizes of MPs detected at different sampling periods for each subdomain [(May 2019: $\left(\chi^{2}(3)=163.734, p=.000\right)$; October 2019: $\left(\chi^{2}(3)=\right.$ $18.974, p=.000)]$. Size frequency distribution of detected plastic particles, regardless of seasonality, was given in Figure. While the sizes of MPs detected in the surface water of river mouth and freshwater surface areas shown similarity, size differences were detected in all other areas in May 2019 (Figure ). In general water column samplers contains smaller MPs. Moreover, size similarity detected between river mouth surface and river mouth water column, fresh water surface water samples in October 2019 period.

The classification of the MPs according to their colours revealed that, out of 13 detected colours only 4 colours composed more than $80 \%$ of the detected plastic particles (Black-27.3\%, White-19.4\%, Red-18.7\% and Blue-16.2\%) (Figure 10). Comparison of the colour variety of the detected particles in the two sampling periods of the study was also indicated same colour pattern for the two periods. Majority of MPs detected within the framework of the study were fiber $(57.1 \%)$ (A3a, C and D) and fragment (32.6\%) (A1a-c and F), while film (Figure $3 \mathrm{~A} 2 \mathrm{a}-\mathrm{d}$ ), paint (Figure $3 \mathrm{~B}$ ) and foam particles (Figure $3 \mathrm{E}$ ) were represented with $5.5 \%, 4.2 \%$ and $0.6 \%$ respectively. Moreover, no change in the proportional shares of the plastic types was observed between sampling periods. A conspicuous situation was the availability of the paint particles only in May 2019 sampling period.

A significant colour difference was detected between subdomains of the study area $\left(\chi^{2}(36)=\right.$ $441.963, p=.000)$. While the rate of the red MPs was $14.2-17.8 \%$ in the sea samples its rate increases to $27.7 \%$ on the river surface samples. Moreover, a higher white MPs existence detected in surface water samples. Rate of the white MPs in the water column samples and surface water samples were ranged between 10.5-
15.3\% and $20.5-25.6 \%$ respectively. Additionally, the proportional share of the blue MPs within each evaluated domain differed. Share of blue MPs in the water column samples obtained from the fishing areas, the water column and water surface samples in the river mouth regions of the freshwater systems under consideration, and the freshwater surface samples were $11.8 \%, 19.7 \%, 7.0 \%$ and $4.4 \%$ respectively. Brown particles, on the other hand, have the highest share with $20.1 \%$ in fishing areas compared to other sub domains.

In terms of MPs types a significant difference was also detected between subdomains of the study area $\left(\chi^{2}(12)=702.249, p=.000\right)$. A detailed examination of the proportional share of the MPs types detected in the subdomains of the study area revealed that, while the amount of fragment MPs in water surface samples was between $32.4-56.2 \%$, it was $7.4-7.7 \%$ in water column samples. Moreover, film MPs proportional share of the water column samples from the river mouth regions was detected to be more than 7 times lower than in other subdomains. Furthermore, while paint MPs were detected more in the water column samples, foam MPs were only detected from freshwater surface samples.

\section{Polymer analysis}

Of the 32 plastics used in the FTIR analysis, 11 $(34.4 \%)$ were film, 11 (34.4\%) were fragment and 10 (31.3\%) were fiber particles. The average spectral match score for the FTIR analysis was 83.2 \pm 3 .8. Based on ATR$\mu \mathrm{FT}-\mathrm{IR}$ analysis results six polymers were detected with in the sub sample of the MPs. Most common polymer was Polypropylene-(PP) with $50 \%$. The encounter rate of other detected polymers in the sample were: Highdensity polyethylene (HDPE) - 12.5\%, Polyester - 3.1\%, Polyethylene (PE) - 21.9\%, Polymethylpentene (PMP) $3.1 \%$ and Polyvinyl alcohol (PVOH) $-9.4 \%$.

Within the scope of the study, plastic particles with characteristic features were encountered. A transparent PE fragment (Figure F) and a PP red fiber (ending in white coloration at both ends) (Figure C) were represented in the samples with 25 and 249 particles respectively. While the fragments were sampled only in the coastal areas, fibers were detected to be distributed to all study area including the fishing grounds. Despite the effort to determine the polymer type of the paint particle (Figure B), which was represented by 659 particles in the study sample, chemical composition and physical state of the particles could not be determined.

\section{Discussion}

One of the main challenges of the researcher need to cope while working on microplastic pollution is controlling the background contamination thorough their studies. Due to its size and ubiquitous distribution, is a necessity to take precautions and control every step (sample collection to laboratory analysis) of the MPs isolation process from the samples (Brander et al., 
2020). Also, to create big data which will make possible to run larger scale meta-analyses and create a dataset which enables the comparisons of the results of different studies, adopting a standardized and harmonized methods is a necessity. To be able to achieve this goal, within the scope of this study field samplings and laboratory studies carried out in accordance published the international guidelines (European Commission, 2013; GESAMP, 2019). Moreover, to prevent the over estimation, background MPs pollution originated from sampling equipment and air contamination were removed from the data set prior to statistical analysis. Though it's important to highlight the existence of high number of paint particles (antifouling components used for hull protection) originated from the research vessel used as it is a known environmental issue and one of the major source of the MPs pollution especially in the busy shipping lanes (Dibke et al., 2021). The share of the paint particles within the detected MPs in the present study was that $21.2 \%$.

Goal of the present study was to reveal the abundance and spatio-temporal distribution of MPs pollution in the three freshwater systems in the study area. Several studies reported increased MPs abundance during the wet season in relation with the high rain fall (Hitchcock, 2020; Napper et al., 2021; Schell et al., 2021; Wong et al., 2020; Xia et al., 2021). Also following flood events known to have an impact on the dramatic increase of the MPs abundance within the vicinities of the river systems located in the north western Mediterranean Sea coastline (Gündoğdu et al., 2018). Though our results indicated no difference between wet and dry season either subdomain of the freshwater systems evaluated in the study area. However, MPs pollution distribution pattern similar to those reported in the literature was detected (Browne et al., 2011). MPs abundance increased in parallel with the population density increase within the basins evaluated. Detected mean MPs abundance from rivers was $0.25 \pm 0.08 \mathrm{MPs} . \mathrm{m}^{-3}$. In comparison to the available literature on MPs load of several European rivers (range: 0.9 - 14.6 MPs. $\mathrm{m}^{-3}$ ) detected MPs abundance was lower than other regions (Guerranti et al., 2020; van der Wal et al., 2015). While the most prevalent polymer type was detected to be polystyrene (PS) in European rivers our results indicated that Polypropylene-(PP) is the dominant type in the study area. PP particle rate range was reported to be $3.45-16.83 \%$ for the European rivers (Danube, Po, Rhine and Dalalven Rivers) (van der Wal et al., 2015).According to the 2019 environmental report of the Antalya province the three freshwater system evaluated within the frame work of the present study are under several anthropogenic factors along their basins, such as tourism, agriculture, aquaculture, densely populated areas and mining activities (ÇŞB 2020). As the available literature indicated variations between water bodies such as city creeks, rivers, estuaries and coastal waters (Luo et al., 2019), it was excepted to detect abundance difference between studied freshwater systems due to the different pollutant potential of the studied basins. However, similar to the seasonal state, in terms of MPs abundance our results indicated no difference between either the freshwater systems or the fishing grounds evaluated. The only exception from this state was the water column samples collected from river mouth region that differ seasonally. It was reported that sedimentation behaviour in the river estuary was related with the vertical distribution of the MPs pollution (Zhou et al., 2021). As it was assumed that increase in the flow rate of the rivers, the MPs load accumulated in the sediment resuspends back to the water column (Schell et al., 2021). In order to better understand the reasons for the seasonal vertical variation of MPs existence in the study area, more detailed future studies focused on the river mouth regions is required. The probable cause of this observed heterogeneous pollution state might be the geographic proximity and similarities of the terrestrial use of the freshwater systems under consideration. Moreover, a more detailed examination of the MPs pollutant potentials of the freshwater systems under consideration, covering the entire basin, is important in terms of revealing the causes of the observed heterogeneous pollution situation.

One weakness of the present study that needs to be expressed, which stands out during the evaluations, was the high standard variation values observed in the dataset. It is recommended for the future studies to increase the repetition samples to avoid the high variation in the data set which cause overshadow effect on regional and temporal MPs abundance differences.

In terms of the size of the MPs detected in the study area the mean size was found to be $1.8 \pm 1.2 \mathrm{~mm}$. Withal a seasonal difference MPs size also detected in the area. As the sampling approach and/or mesh size of the sampling/filtration equipment known to be the main factor for the detectable size range in the study areas (Song et al., 2014), comparison of the detected MPs size with those detected in other areas is a troublesome approach. Though seasonal MPs length differences, which we also have detected in our study, have been reported from the surface water samples collected from transboundary Ganges River (India and Bangladesh) (Napper et al., 2021). One other important natural dynamic that is important to be considered is the hydrodynamic disturbances in the study region as it is the main driver for movement of plastic particles between sediment and water column this phenomenon was influential especially on smaller sized MPs (Xia et al., 2021).

Colour is one of the main characteristic which most of the researchers focused in order to both determine the potential risk of the MPs to biota (as they are easily mistaken as food items) and its potential to provide information in identifying the source of the pollution (Yang et al., 2021). It was reported that white and transparent plastic particles were constitute a large 
portion of the MPs detected in the freshwater systems (Wong et al., 2020; Yang et al., 2021). Though in addition to white particles black, red and blue particles were constitute $62.2 \%$ of the detected MPs in the present study. Same colour pattern was also detected from Ganges River (Napper et al., 2021). In most of the studies conducted to date, it is stated that fiber and fragment particles were the most common type of MPs in freshwater systems (Napper et al., 2021; Wong et al., 2020; Yang et al., 2021). In accordance with this findings fiber and fragment MPs constitute $89.7 \%$ of the MPs detected in this study. In addition to physical characterization, polymer characterization is a frequently preferred and a fundamental method in microplastic studies (Hartmann et al., 2019). A wide range of plastic polymer types known to compose the MPs in the marine environment. According to the Plastics Europe four polymer types (polypropylene, lowdensity and high-density polyethylene, polyvinyl chloride) were the most produces due to high demand. In conformance with this information, polymer analysis of the detected MPs in study were revealed that half of the MPs were PP. HDPE and PE constitute $15.6 \%$ of the remaining particles. The results we obtained from the present study support the knowledge of polymer types and ratios that are likely to be encountered in the natural environment expressed in the literature.

\section{Conclusion}

The aim of the present study was to detect the abundance and spatio-temporal distribution of MPs pollution in the three freshwater systems and their vicinities in the Antalya Bay. Results of the study has the feature of being is the first data on the state of microplastic pollution in the study area. Our results indicated a homogeneous MPs pollution existence both spatial and temporal point of view. Based on the results obtained from this study, future studies that take into account the terrestrial use and the prevailing physical factors in the region can be carried out in the study area. In addition to the abundance and particle characteristic information share in the previous section several points were needed to be highlighted to be able to contribute to future studies on the subject. Particles that stand out due to their characteristic features will contribute significantly to the efforts to identify the source of pollution and to the solution of pollution at the source. It is important to pay attention to such particles and to evaluate these particles separately when necessary. Moreover, as a part of Quality Assurance and Quality Control in MPs studies focused on occurrence of MPs in de environment, it is important to consider the contamination originating from the sampling equipment (research vessels, laboratory equipment, etc.) in the evaluations in order pollution assessments. Key to successful initiatives that producing effective results is to adopt effective plastic recovery systems activities such as domestic use, fishing, maritime transport and tourism (Aytan et al., 2020; Oztekin et al., 2020).

\section{Ethical Statement}

I declare that there have been no known competing financial interests or personal relationships that could have appeared to influence the work reported in this paper. Present study was carried out with approval of Akdeniz University, Faculty of Fisheries, Animal Experiments Local Ethics Committee (Protocol number: 2018.12.02).

\section{Funding Information}

This research was supported by (Akdeniz University Scientific Research Projects Coordination Unit) under grant (FBA-2019-4449) (Title: Assessment of Microplastic Pollution Status and Its Impacts on Biota in Coastal Habitats and Commercial Fishing Grounds of Gulf of Antalya) and carried out under the T.C. Ministry of Agriculture and Forest legal research permit: (Number: 7852565-140.03.03-E.1351584).

\section{Author Contribution}

Field work, laboratory work, statistical analysis, preparation process of the manuscript

\section{Conflict of Interest}

The author(s) declare that they have no known competing financial or non-financial, professional, or personal conflicts that could have appeared to influence the work reported in this paper.

\section{Acknowledgements}

I wish to extend my gratitude to Dr. Sinan MAVRUK and Idris KORALTAN for the technical help with field work and sample processing steps, Dr. S. Fatih ÖZMEN for his contribution on the polymer analysis carried out within the scope of the study. Also, I thank to R/V "Akdeniz Su" crew for their efforts in on board work.

\section{References}

Aytan, U., Sahin, F. B. E. \& Karacan, F. (2020). Beach litter on sarayköy beach (Se black sea): Density, composition, possible sources and associated organisms. Turkish Journal of Fisheries and Aquatic Sciences, 20(2), 137145. https://doi.org/10.4194/1303-2712-v20_2_06

Brander, S. M., Renick, V. C., Foley, M. M., Steele, C., Woo, M., Lusher, A., Carr, S., Helm, P., Box, C., Cherniak, S., Andrews, R. C. \& Rochman, C. M. (2020). Sampling and Quality Assurance and Quality Control: A Guide for Scientists Investigating the Occurrence of Microplastics Across Matrices: 
https://Doi.Org/10.1177/0003702820945713, 74(9), 10 99-1125. https://doi.org/10.1177/0003702820945713

Browne, M. A., Crump, P., Niven, S. J., Teuten, E., Tonkin, A., Galloway, T. \& Thompson, R. (2011). Accumulation of Microplastic on Shorelines Woldwide: Sources and Sinks. Environmental Science and Technology, 45(21), 91759179. https://doi.org/10.1021/ES201811S

Cózar, A., Sanz-Martín, M., Martí, E., González-Gordillo, J. I., Ubeda, B., Gálvez, J. Á., Irigoien, X. \& Duarte, C. M. (2015). Plastic Accumulation in the Mediterranean Sea. PLOS ONE, 10(4), e0121762. https://doi.org/10.1371/JOURNAL.PONE.0121762

Dibke, C., Fischer, M. \& Scholz-Böttcher, B. M. (2021). Microplastic Mass Concentrations and Distribution in German Bight Waters by Pyrolysis-Gas Chromatography-Mass

Spectrometry/Thermochemolysis Reveal Potential Impact of Marine Coatings: Do Ships Leave Skid Marks? Environmental Science \& Technology, 55(4), 2285-2295. https://doi.org/10.1021/ACS.EST.0C04522

European Commission. (2013). MSDF Guidance on Monitoring Marine Litter. https://doi.org/10.2788/99475

GESAMP. (2019). Guidelines for the monitoring and assessment of plastic litter in the ocean (Kershaw P.J., Turra A. and Galgani F. editors), (IMO/FAO/UNESCOIOC/UNIDO/WMO/IAEA/UN/UNEP/UNDP/ISA Joint Group of Experts on the Scientific Aspects of Marine Environmental Prote. Rep. Stud. GESAMP, no 99, 130p. http://www.gesamp.org/publications/guidelines-forthe-monitoring-and-assessment-of-plastic-litter-in-theocean

Guerranti, C., Perra, G., Martellini, T., Giari, L. \& Cincinelli, A. (2020). Knowledge about Microplastic in Mediterranean Tributary River Ecosystems: Lack of Data and Research Needs on Such a Crucial Marine Pollution Source. Journal of Marine Science and Engineering 2020, Vol. 8, Page 216, 8(3), 216. https://doi.org/10.3390/JMSE8030216

Gündoğdu, S., Çevik, C., Ayat, B., Aydoğan, B. \& Karaca, S. (2018). How microplastics quantities increase with flood events? An example from Mersin Bay NE Levantine coast of Turkey. Environmental Pollution, 239, 342-350. https://doi.org/10.1016/j.envpol.2018.04.042

Hartmann, N. B., Hüffer, T., Thompson, R. C., Hassellöv, M., Verschoor, A., Daugaard, A. E., Rist, S., Karlsson, T., Brennholt, N., Cole, M., Herrling, M. P., Hess, M. C., Ivleva, N. P., Lusher, A. L. \& Wagner, M. (2019). Are We Speaking the Same Language? Recommendations for a Definition and Categorization Framework for Plastic Debris. Environmental Science \& Technology, 53(3), 1039-1047. https://doi.org/10.1021/ACS.EST.8B05297

Hitchcock, J. N. (2020). Storm events as key moments of microplastic contamination in aquatic ecosystems. Science of The Total Environment, 734, 139436. https://doi.org/10.1016/j.scitotenv.2020.139436

Liubartseva, S., Coppini, G., Lecci, R. \& Clementi, E. (2018). Tracking plastics in the Mediterranean: 2D Lagrangian model. Marine Pollution Bulletin, 129(1), 151-162. https://doi.org/10.1016/J.MARPOLBUL.2018.02.019

Luo, W., Su, L., Craig, N. J., Du, F., Wu, C. \& Shi, H. (2019). Comparison of microplastic pollution in different water bodies from urban creeks to coastal waters. Environmental Pollution, 246, 174-182. https://doi.org/10.1016/J.ENVPOL.2018.11.081

Napper, I. E., Baroth, A., Barrett, A. C., Bhola, S., Chowdhury, G. W., Davies, B. F. R., Duncan, E. M., Kumar, S., Nelms, S. E., Hasan Niloy, M. N., Nishat, B., Maddalene, T.,
Thompson, R. C. \& Koldewey, H. (2021). The abundance and characteristics of microplastics in surface water in the transboundary Ganges River. Environmental Pollution, 274, 116348 https://doi.org/10.1016/J.ENVPOL.2020.116348

Nie, H., Wang, J., Xu, K., Huang, Y. \& Yan, M. (2019, December 15). Microplastic pollution in water and fish samples around Nanxun Reef in Nansha Islands, South China Sea. Science of the Total Environment; Elsevier B.V. https://doi.org/10.1016/j.scitotenv.2019.134022

Oztekin, A., Bat, L. \& Baki, O. G. (2020). Beach litter pollution in Sinop Sarikum Lagoon coast of the southern black sea. Turkish Journal of Fisheries and Aquatic Sciences, 20(3), 197205. https://doi.org/10.4194/1303-2712-v20_3_04

Parker, L. (2019). Plastic pollution facts and information. National Geographic. https://www.nationalgeographic.com/environment/arti cle/plastic-pollution

Schell, T., Hurley, R., Nizzetto, L., Rico, A. \& Vighi, M. (2021). Spatio-temporal distribution of microplastics in a Mediterranean river catchment: The importance of wastewater as an environmental pathway. Journal of Hazardous Materials, 420, 126481. https://doi.org/10.1016/J.JHAZMAT.2021.126481

Song, Y. K., Hong, S. H., Jang, M., Kang, J.-H., Kwon, O. Y., Han, G. M. \& Shim, W. J. (2014). Large Accumulation of MicroSized Synthetic Polymer Particles in the Sea Surface Microlayer. Environmental Science and Technology, 48(16), 9014-9021. https://doi.org/10.1021/ES501757S

TÜBITAK MAM ÇTÜE. (2013). HAVZA KORUMA EYLEM PLANLARININ HAZIRLANMASI PROJESI ANTALYA HAVZASI. In 2013. https://www.tarimorman.gov.tr/SYGM/Belgeler/havza koruma eylem planları/Antalya_web.pdf

UNEP, G.-A. (2016). Marine Litter Vital Graphics I GRIDArendal. In UN-Environment, GRID-Arendal. https://www.grida.no/publications/60

van der Wal, M., van der Meulen, M., Tweehuijsen, G., Peterlin, M., Palatinus, A., Kovac, M., Coscia, L. \& Krzan, A. (2015). SFRA0025: Identification and Assessment of Riverine Input of (Marine) Litter Final Report for the European Commission DG Environment under Framework Contract No. In Portal.Helcom. Fi (Issue April). www.eunomia.co.uk

Wang, G., Lu, J., Li, W., Ning, J., Zhou, L., Tong, Y., Liu, Z., Zhou, H. \& Xiayihazi, N. (2021). Seasonal variation and risk assessment of microplastics in surface water of the Manas River Basin, China. Ecotoxicology and Environmental Safety, 208, 111477. https://doi.org/10.1016/J.ECOENV.2020.111477

Wong, G., Löwemark, L. \& Kunz, A. (2020). Microplastic pollution of the Tamsui River and its tributaries in northern Taiwan: Spatial heterogeneity and correlation with precipitation. Environmental Pollution, 260, 113935.

https://doi.org/10.1016/J.ENVPOL.2020.113935

Xia, F., Yao, Q., Zhang, J. \& Wang, D. (2021). Effects of seasonal variation and resuspension on microplastics in river sediments. Environmental Pollution, 286, 117403. https://doi.org/10.1016/J.ENVPOL.2021.117403

Yang, L., Zhang, Y., Kang, S., Wang, Z. \& Wu, C. (2021). Microplastics in freshwater sediment: A review on methods, occurrence, and sources. Science of The Total Environment, 754, 141948. https://doi.org/10.1016/J.SCITOTENV.2020.141948 
Zhou, Z., Zhang, P., Zhang, G., Wang, S., Cai, Y. \& Wang, H. (2021). Vertical microplastic distribution in sediments of Fuhe River estuary to Baiyangdian Wetland in Northern
China.
280,
130800 .

https://doi.org/10.1016/J.CHEMOSPHERE.2021.130800 